\title{
Curbing family planning in Iran: an appraisal of Bill 446
}

As a policy response to the low fertility rate, Iran's Parliament proposed Bill 446, which bans surgical sterilisations used solely to limit births. The Bill's aim is to raise the country's low fertility rate that has fallen to 1.6 births per woman. ${ }^{1}$ There is no doubt that Iran's population control policy needs to be revised to increase fertility levels, however recent data (Figure 1) indicate that the draconian policy of banning sterilisation will not raise the fertility rate, and it may also adversely increase unintended births, induced abortions and maternal mortality.

The individuals who proposed Bill 446 and those who have expressed grave concerns about its adverse health effects $^{3}{ }^{4}$ both wrongly give too much importance to the impact of government-sponsored family planning services on the recent declining fertility rate and preventing unpleasant reproductive outcomes. Currently, only 22\% 


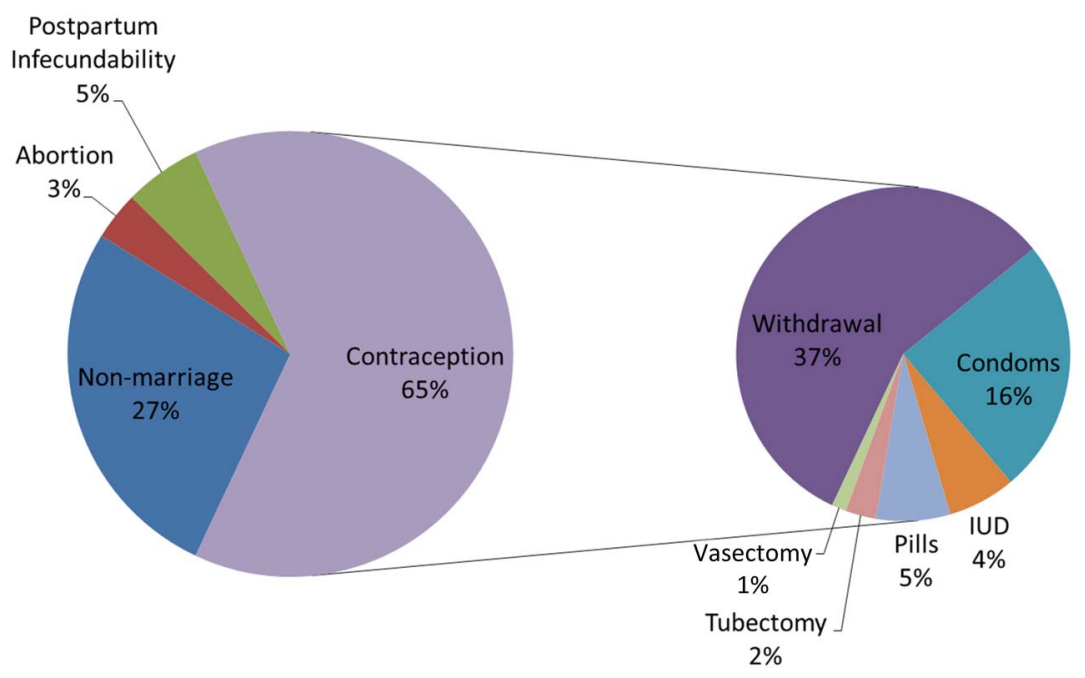

Figure 1 Relative contribution of non-marriage, effective use of contraceptive methods, induced abortion and postpartum infecundability to the declining fertility rate in Tehran, Iran in 2014 . $^{2}$ IUD, intrauterine device.

of married women of reproductive age attend 'health houses' to receive family planning services; the others largely use male contraceptives. ${ }^{5}$ Consequently, as Figure 1 illustrates, only $7 \%$ of the reduction in fertility can be attributed to the effective use of medical sterilisation and the intrauterine device as the two major contraceptive methods funded by the government. The other $93 \%$ of the reduction is due to delaying marriage, use of male contraceptives (e.g. withdrawal and condoms) and the pill, induced abortion and postpartum infecundability, all of which have less to do with the government's family planning programme. Pills and condoms are accessible in drugstores at minimal cost, and withdrawal is always freely available. Besides, medical sterilisations contribute to fertility reduction by only $3 \%$; therefore, even if surgical sterilisations are banned, the fertility rate will be very unlikely to rise.

However, if Bill 446 is approved, the most vulnerable population will be socioeconomically disadvantaged women who live in rural and poor settings, and who have two or more children and want to stop childbearing. ${ }^{5}$ This likely drawback of Bill 446 can be alleviated by the newly developed 'Reproductive Health' programme in Iran's Ministry of Health, which has replaced the old population control programme. Under the new programme, family planning services (except surgical sterilisations) are currently delivered to women by the existing network of 'health houses', to enhance maternal, infant and child health through appropriate birth spacing and child nutrition (according to the Director General of
Population, Family \& School Health Department in Iran's Ministry of Health). ${ }^{5}$

Though Bill 446 was proposed hastily and unprofessionally, the new reproductive health programme is promising and would appear to take care of Iran's citizens' reproductive health needs and rights.

Amir Erfani, PhD, MA

Associate Professor of Demography, Fertility and Reproductive Health Researcher, Department of Sociology, Nipissing University, North Bay, Ontario, Canada; amire@nipissingu.ca

Competing interests None declared.

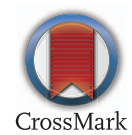

J Fam Plann Reprod Health Care 2015;41:317-318. doi:10.1136/jprhc-2015-101254

\section{REFERENCES}

1 Erfani A. Fertility in Tehran City and Iran: rates, trends and differentials [in Persian]. Popul Stud 2013;1:87-107.

2 Erfani A. Tehran Survey of Fertility, 2014: Final Report. Tehran, Iran: National Population Studies and Comprehensive Management Institute, Ministry of Science, Research, and Technology, 2015.

3 Aloosh M. Family planning in Iran: author's reply. Lancet 2015;385:1072.

4 Amnesty International. You shall procreate: attacks on women's sexual and reproductive rights in Iran. 2015. https://www.amnesty.org/ en/documents/MDE13/1111/2015/en/ [accessed 25 March 2015].

5 Motlagh ME, Eslami M. A round-table interview on population. Fars News Agency, 29 January 2014. http://www.farsnews.com/ newstext.php?nn=13921109000105 [accessed 25 March 2015]. 